\title{
Research on Faculty and Staff Development in the Context of Obtaining International Accreditation
}

\author{
Xia Xu \\ Business College of Beijing Union University, Beijing, China \\ Email: xuxiajy0209@163.com
}

How to cite this paper: $\mathrm{Xu}, \mathrm{X}$. (2021). Research on Faculty and Staff Development in the Context of Obtaining International Accreditation. Open Journal of Social Sciences, 9, 151-156.

https://doi.org/10.4236/jss.2021.92010

Received: January 20, 2021

Accepted: February 15, 2021

Published: February 18, 2021

Copyright (c) 2021 by author(s) and Scientific Research Publishing Inc. This work is licensed under the Creative Commons Attribution International License (CC BY 4.0).

http://creativecommons.org/licenses/by/4.0/

\begin{abstract}
AACSB accreditation has specific requirements for faculty and other administrative staff. In accordance with the mission of the college's accreditation and the features of faculty and staff members, Business College has developed criteria for the classification of teachers and organized relevant training. After several years, there are still some problems in improving the system of faculty and staffs, and we hope to make progress step by step in five aspects.
\end{abstract}

\section{Keywords}

International Accreditation, Faculty and Staff, Development

\section{Introduction}

The initial Self-Evaluation Report (iSER) submitted by Business College of Beijing Union University in 2016 was reviewed by the AACSB Initial Accreditation Committee (IAC) and approved. This marks a new stage in our AACSB accreditation work-from top-level design, strategic planning and phased demonstration to down-to-earth implementation. AACSB accreditation requires a faculty that is sufficient in quantity and normative in quality to achieve the college's mission and strategic plan (Liu \& Ma, 2014). Besides, appropriate other positions are also needed to fulfill the mission. In this accreditation standard, there are clear criteria for the definition of a business school faculty, as well as for teacher resource and personnel support. The teaching, research and service capabilities of the faculty and staff are therefore crucial to achieving the AACSB mission of "fulfilling social responsibility, promoting applied innovation, cultivating business backbone and serving regional development" (Chen \& Zheng, 2019). 
How can we adapt to the requirements of AACSB accreditation and actively participate in it by taking into account the demand of the college and the feature of teachers and staff so that all the faculty and staff can make their own contribution to an effective accreditation? Therefore, the college should set up a platform for the growth of faculty and staff and improve the mechanism for their progress on the basis of respecting the law of their growth, so that they can make progress on a positive track. In this way, faculty members can meet the requirements of AACSB accreditation and get advice that is valuable to their career planning.

\section{Present Situation and Features of Teachers and Staffs in Business College}

In recent five years, along with the restructuring of its majors and the merging of departments, the composition of the college's staffs is constantly varying, showing a general pattern of fewer new personnel and decreasing of old employees. Specifically, in the past five years, there have been 24 new staff members, 12 transferred employees, 42 employees transferred to other positions in the university and 33 retirees. The college currently has 162 serving staff members of which $70 \%$ are women and their average age is 42 . Among them, 21 female staff members have given birth to their second child since the release of the two-child policy. There are three departments, one sector and six majors. Also, the college has 64 professional teachers, $62.5 \%$ of whom have senior titles and $82.8 \%$ of whom are $\mathrm{PhD}$. We are one of the colleges that own high proportion of teachers with senior professional titles and doctoral degree. Following the revision of the new criteria for promotion to professional and technical posts in 2017, fewer professional teachers have been able to meet the new criteria and there have been limited promotion indexes of senior professional title in the last two years.

The college has developed relevant teacher classification criteria for teachers based on its own situation and the mission, and assigned all professional teachers in office to each of the four categories SA (Scholarly Academics), SP (Scholarly Practitioners), PA (Practice Academics) and IP (Instructional Practitioners) according to the criteria. Teachers found a clear direction for their progress according to their own situation. The college has also sorted out the actual situation of each major and supported teacher's future development in line with their characteristics At present, the difficulty among teachers also lies in publishing first-class academic papers, especially for those who are old and enjoy senior professional titles. Other staff members should do their best to ensure the smooth running of the accreditation process and to assist in completing the initial accreditation. The Academic Affairs Office assists with AOL testing. The Personnel Office assists with faculty development. And the Research Department provides the basis for the formation of faculty classification criteria to promote teacher's research process and supervises them to meet the classification criteria. 
In the future, all aspects of the college will be inspected, interviewed by experts. Besides, faculty and staff should report the situation to them in English. In addition to completing the tasks at hand, faculty and staff should improve their English spontaneousmy. In this way, we are able to be assessed by the AACSB accreditation experts.

\section{Current Issues in Extensively Reflected by Faculty and Staff}

In order to effectively solve problems in working life of teachers and staff, we have collected the following problems reflected by teachers and staffs through discussions with teachers of various disciplines and interviews with staff.

\subsection{Stressful}

Faculty and staff generally agree that the current work is very stressful, especially for young female staff who not only have to bear the heavy workload of the school, but also the burden of raising children in the family. Nowadays, it is tough for two-kids family because the current social environment places increasing requirements on parents to raise their children. Consequently, they feel physically and mentally exhausted.

\subsection{Uncertainty about the Future of the University}

The school's relocation has been long overdue. For ten years there have been rumors about removal though a relocation plan has been scheduled in Beijing. Faculty and staff were confused about their future work address, especially for families with children, and this has an impact on teachers' mind in teaching.

\subsection{Lack of Effective Extension to the Examination and Related Promotion and Appointment Documents of Faculty and Staff}

Currently, the University operates a post appointment system that personnel will be appointments every four years. The 2017 appointment document is a substantial upgrade in the 2013 appointment assessment document. In addition, the prerequisites for promotion to professional and technical positions in the new 2017 pilot documents have also been generally upgraded its requirements. Teachers feel that the demands on them are too high to accomplish, so they are lack of motivation. On the contrary, many of them will simply muddle through and show slackness in their current profession since they cannot meet the requirements.

\subsection{Single Standard of Assessment plus Increasing Volume of Assessment}

Annual assessment, tenure assessment and professional and technical promotion requirements are the guidance in the work of faculty and staff. They believe that 
the current standards are entirely based on the position, requiring a per capita amount of class hour and an apportionment of research funds. Since everyone is working together on teaching and research along with the constantly increasing requirements to the quantitative and qualitative of research. No one can distinguish themselves in this environment.

\section{Suggestions for Solving the Problem}

In this context, the college has to combine its mission to further optimize and construct its faculty on the basis of the accreditation standards, and further enable faculty and staff to participate in the combination of accreditation and title promotion. After discussion and questionnaire survey, we collected some solutions. We have adopted the following strategies in the hope that they will effectively address the above issues.

\subsection{Relieving the Stress of Faculty and Staff}

The heavy workload, increased competition and stress in work and life have caused serious physical and mental exhaustion among faculty and staff. And they are poor at regulating themselves. In particular, many of the young and middle-aged faculty and staff are highly educated and highly qualified. Usually, they are responsible for teaching, research and management, which means they bore too much stress such as heavy teaching tasks, busy research work, as well as facing many problems such as promotion of titles and family work. Research has also shown that the stress received by individuals can greatly affect mental health (Zhu et al., 2008). Therefore, there should be greater control of people with health-risking stress and greater attention to people with moderate stress to prevent them from converting to the pressure that may risk their health. In the daily management, it is recommended that the college union organize more outdoor activities to allow everyone to relax. The college should also try to create a pleasant working environment and set up a learning-oriented team to involve stress (Zhang \& Zhou, 2019).

In addition, the majority of female faculty and staff are the mainstream of the college's developing team. In fact, they are increasingly playing an important role in education, administration and research, and undertaking the same tasks as male faculty or staff. But they do, after all, have different physical bases and family burdens than male faculty and staff. Therefore, the university should pay attention to them through various channels, such as organizing lectures about parenting, psychological adjustment methods, and women health management and other channels to guide female faculty or staff to reduce their pressure.

\subsection{Clarify the Direction and Relocation Site of the University as Soon as Possible}

Studies show that the growth of a company is highly correlated with the engagement of employee (Lu, 2013). How companies can improve their competi- 
tiveness and build the confidence of their workers toward company is a question that business managers should consider, which is the same for the development of university faculty and staff. The removal of university site is like dropping a boot and waiting for the other one to drop at some point. I hope that the school will give the teachers a direction for the future development of the university as soon as possible, so that they will no longer be frightened and will be able to hold on to their posts without fear. Accordingly, the negative effects caused by the unsettling factors will be eliminated.

\subsection{Eliminate Negative Emotions and Improve Morale and Cohesion}

At present, there are staff members in individual posts who are unruly and too forceful in their personalities to complete their tasks by complying with the university rules. They become impediments and risk in managing the school. If such behavior is allowed to develop, the negative emotions will not only affect the motivation of the individual, but also "infect" other members of the organization, causing undue pressure and affecting its "morale" and cohesion (Pan, 2007).

\subsection{Form Diverse Assessment Schemes}

In AACSB accreditation, there are separate standard requirements for each type of teacher. They will be categorized and assessed on the basis of their individual characteristics. In fact, the purpose of performance assessment for faculty and staff is not to define or grade them, but to try to motivate people to do better in teaching. Therefore, it is hoped that the single-criteria assessment system will be diversified so that teachers with different characteristics will have various progress goals, which may give full play to their motivation. For example, teachers who are good at entrepreneurship are encouraged to lead their students, to mentor them in entrepreneurship, and to assess their entrepreneurial performance rather than publishing papers and completing projects. In addition, it is recommended that schools should consider the interface and transition before and after the documents to avoid confusing everyone for a while when forming assessment documents.

\subsection{Applying Multiple Channels to Support Faculty and Staff to Improve English}

English is no longer required for the promotion to professional and technical posts. However, AACSB accreditation because of its international nature, requires a decent spoken English for faculty and staff in the accreditation process. Since bilingual teaching is also a requirement for teachers. Improving spoken English is a sustained process and does not happen overnight. Therefore, in conjunction with the experience of the college's previous English training for managers, teachers and staff should insist on learning English. 


\section{Conflicts of Interest}

The author declares no conflicts of interest regarding the publication of this paper.

\section{References}

Chen, J. B., \& Zheng, L. (2019). Research on the Training Mode of Business Backbones from the Perspective of Internationalization. Beijing Education (Higher Education), No. 1, 66-69.

Liu, Y., \& Ma, A. M. (2014). Analysis on the Basic Framework and Characteristics of AACSB Certification Standard. Shanghai Education Evaluation Research, No. 4, 23-27.

Lu, L. (2013). Investigation on the Factors Influencing Enterprise Employees' Professional Dedication and Research on Promotion Strategies. Journal of China Institute of Labor Relations, 27, 62 .

Pan, Y. X. (2007). The Negative Effects of Teachers' Work Stress and Its Intervention Strategies. Contemporary Educational Science, 23, 60.

Zhang, J. L., \& Zhou, H. L. (2019). Three Dimensions of Special Education Teachers' Work Family Conflict and Its Mitigation Path. Chinese Journal of Education, No. 8, 76-80.

Zhu, J. S., Li, Y. Q., Wang, X. Y., et al. (2008). Investigation on Mental Health Status of Staff with Senior Titles in Zhejiang University. Research and Practice of Health Care Medicine, 5, 42. 